\title{
Plans for Conserving the Wildlife of Hong Kong
}

\author{
By P. M. Marshall \& J. G. Phillips
}

With three mammals certainly extinct in the last seventeen years, two probably extinct and several more now on the danger list, there is urgent need for an investigation into the status of Hong Kong's wildlife and the setting aside of reserves for its conservation. Building and industrial development are increasingly destroying some of the hitherto unspoiled areas, and a group of people in Hong Kong have drawn up plans for a national park and several small nature reserves, including an island one on which it would be possible to re-establish local species of animals which could be used to re-stock other areas. Professor Phillips is head of the Department of Zoology in the University of Hong Kong of which Dr Marshall is also a member.

HONG KONG had an unpromising beginning. In 1841, Lord Palmerston, the then Foreign Secretary, described it as "a barren island with hardly a house upon it", but despite his protestations Hong Kong was ceded to the Crown under the Treaty of Nanking in 1842 , and in 1898 a further $365 \frac{1}{2}$ square miles of surrounding islands and mainland China were leased to the Crown for 99 years. Under British rule the Colony has grown and prospered. There are now 3.7 million people within its 398 square miles, making it one of the most densely populated areas in the world. Yet the visitor is always surprised by the fact that the greater part of Hong Kong is unpopulated and superficially unspoiled. The reason is immediately apparent from a visit to the twin cities of Victoria and Kowloon, which, with the other coastal fringes of the harbour, contain over 70 per cent. of the population. Living accommodation has been restricted to these areas because there is very little suitable flat land elsewhere, and the policy has been to build upwards rather than outwards. With new building techniques, however, it is becoming possible to develop hitherto unworkable sites, and the urban areas are spreading. Vast areas of hillside are being levelled for building, and in some cases reduced almost to sea level and the debris used to reclaim land from the sea.

It is not only the high density living areas that are increasing; with industrialisation, factories and new industrial towns are springing up all over the colony, invading the countryside and threatening to turn the Colony into what has been described as a concrete jungle. Our hillsides and open spaces are yielding to the urban spread, and exceedingly beautiful areas which today are taken for granted are disappearing. In some measure this is inevitable, but the countryside is also being destroyed even where no building is taking place. 
Up to a thousand years ago tropical rain forest covered the Hong Kong region.* Wildlife was prolific; elephants, tigers and leopards roamed the hillsides, and there were crocodiles and dugongs in the estuaries. Apart from a few aboriginal coastal traders, and scattered garrisons of the T'angs the region was almost uninhabited. In the forests Yoa tribes are reputed to have been present. Although there is little evidence, it is probable that these hill tribes lived by clearing areas of the forest, planting a few crops of upland rice, and when the soil was exhausted moving on to clear and burn other areas. This method of shifting cultivation is still practised by hill tribes in Borneo today. Later, in the Sung dynasty, the descendants of the Han came and formed settled communities in the valleys; most of them were farmers, they drained the land and farmed permanent wet paddies. They also kept pigs and cattle and planted vegetables. The Han, now known as Punti or local people, were later joined by the Hakka or guest people, also predominantly farmers. Today the Punti and Hakka are still living in the valleys, farming much as they have done for centuries. To discourage the more dangerous wildlife, the Punti burnt vast areas of forest and destroyed large numbers of animals. Only the smaller mammals and a number of birds and reptiles have survived. One small temple just over the border from Hong Kong marks the spot where a Buddhist pagoda was built over a huge pile of elephant bones in order to placate the elephants that were doing great damage to crops.

\section{Steady Destruction of the Countryside}

The deforestation from 920 A.D. onwards has severely affected the vegetation and the soil, and possibly also the climate. Today in the rural areas the mountain peaks and hillsides are covered with low scrub and grassland, with a poor soil. The climate, with torrential rains in summer and drought in winter, does not encourage lush vegetation, and the secondary growth of conifers that has developed tends to impoverish the soil by podsolisation, which, in many places, has led to deep erosion gullies. Moreover, the farmers, by grazing cattle on the hillsides and collecting firewood, successfully prevent the natural regeneration of hardwoods, while bush and grass fires, which they often start deliberately in order to dry out the brushwood and force the growth of green shoots for the cattle, further reduce the cover, and so does the spill from wildcat wolfram mines. Once the soil is exposed erosion quickly follows. Add to all this the carelessness of weekend picnickers, and one has, in brief, the reasons why our countryside is being destroyed. The few mammals and birds that remain are being hunted and trapped, either for pleasure or for the high prices they command as food or for medicinal purposes. We have no accurate estimate of the faunal decline, but very noticable changes have been observed both by naturalists and hunters even in the last 10 years.

* Information taken in the main from Balfour, S.F. (1940-41) T'ien Hsia Vol. XI No. 4, pages 330-352 and No. 5, 440-464. 


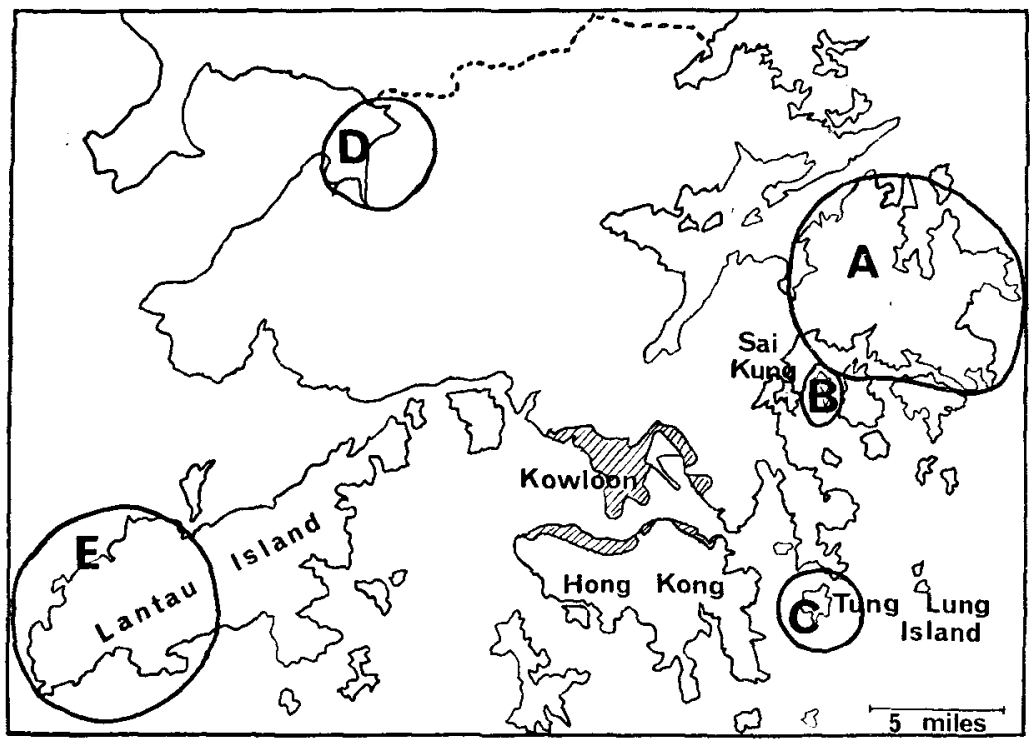

All these considerations point to an urgent need for nature conservation and the creation of national parks and nature reserves. In some measure the animals and plants are protected by laws which prohibit the capture, possession, killing or export of certain animals, and the picking of certain plants such as the Chinese new year flower. Also, all the animals and plants in the large catchment areas which provide the Colony with water are protected. The problem lies, however, in enforcement. The areas are large and the Government officials charged with their maintenance are too few. But the problems we face can be resolved. The Department of Agriculture and Fisheries is active in the afforestation of eroded areas, particularly in the water catchment regions, and the Government has made a start with an overall plan for urban and industrial expansion. Through such planning, green areas could be left unspoiled.

To ensure that all natural green spaces should not be abandoned several interested people met to formulate a policy, albeit unofficial, for the establishment and maintenance of national parks and nature reserves. Support for this scheme is growing and we have reason to believe that when our plans are presented to Government they will receive sympathetic consideration.

The proposals involve two main parts of Hong Kong. First, it is hoped to designate a National Park in the Sai Kung Peninsula (marked A on the map), north of Port Shelter and East of Sai Kung village. Because of its obvious limitations in size the fullest use must be made of the area. To cater for all the people in Hong Kong it is planned to divide the peninsula in an unobtrusive way into three zones. The first would provide parking and recreational facilities for those who 
wish to drive the family car to a place of beauty, and, without expending much energy, enjoy an afternoon in the open air. The second, no more than a mile or two in depth, would have its pleasant walks and woodland paths surfaced for easy access. The third zone would cover the rest of the peninsula and be provided with trailway rest centres in the remotest parts. This third zone would provide for the naturalist, rambler, boy scout and youth clubs a large area for their recreational activities.

Such a Park would aot as a "lung" for the industrial areas just as the catchment areas do today, the important difference being that with adequate supervision, its recreational, educational and aesthetic benefits would remain for future generations to enjoy. Such a park would force economical utilisation of land. Unfortunately, it would stop the building of luxury apartments and detached houses surrounded by gardens, and prevent development in that area. In return, however, it would make available to all the people of Hong Kong some green spaces, which in time would otherwise be available to none.

\section{Suggested Nature Reserves}

The second less ambitious but equally important suggestion involves the designation of several small areas as nature reserves. One island near Hong Kong, Tung Lung Island $(C)$, seems ideally suited for this. It is close to the University and can be reached by launch or junk in 20 minutes from Shek $O$. Since there are few people living on Tung Lung, it would be comparatively easy to re-establish local species of animals there which could then act as reservoirs for restocking other parts of the Colony. With careful supervision Tung Lung could be opened to the public. Other areas under consideration are the western tip of Lantau Island (E), the largest of the islands, Sharp Island (B) which is surrounded by shallow protected waters with abundant corals, and the Mai Po marshes (D).

Lantau is a hilly area and is one of the few places where wild boar Sus scrofa chirodonta and muntjac deer Muntiacus reevesi are still to be found. In contrast, Mai Po is a flat area of salt pans and mangrove swamp, where duck farms and fish ponds co-exist, and of particular interest to bird watchers. Numerous migrants, including the Terek sandpiper Tringa terek, the chestnut bittern Ixobrychus cinnamomeus and the spotted-bill pelican Pelecanus roseus, spend part of the year there, and close by are the haunts of a number of exotic resident birds such as the beautiful blue magpie Urocissa erythrorhyncha and the koel Endynamis scolopacea chinensis.

The disappearing mammals of Hong Kong include the wild boar and the Reeves' muntjac deer, besides a number of unusual and little known ones such as the Chinese pangolin Manis pentadactyla whose scales and meat are unfortunately used in Chinese medicines. The pangolin's armour plating is no protection against man, and as it tends to move noisily in the undergrowth it is easy to catch. It is probably still relatively abundant in the inaccessible regions of the Sai Kung 
peninsula and there are a few left on Hong Kong Island in the Tai Tam reservoir district, but it is none the less in urgent need of protection.

Extinet or Nearly So

Until recently three species of civet were to be found in the Colony: the large Indian civet Viverra zibetha, the small Indian civet Viverricula indica and the masked palm civet Paguma larvata of which only the last is holding its own. There have been very few records of the first two since 1959. The South China Tiger Panthera tigris amoyensis, the Asiatic leopard Panthera pardus fusca and the Asiatic wild dog Cuon alpinus lepturus have all disappeared from the Colony in the last 17 years. The last known leopard to visit us was shot 8 miles from Sha Tau Kok in December, 1957. Other mammals of interest which apparently have already disappeared are the Eastern Chinese otter Lutra lutra chinensis and the crab-eating mongoose Herpestes urva. The last otter was recorded in February, 1960, and the last crabeating mongoose in 1961 . These animals are still occasionally imported into Hong Kong for food. The Chinese ferret-badger Melogale moschata and the Chinese leopard cat Felis bengalensis chinensis are present in small numbers, as is the crestless Himalayan porcupine Hystrix hodgsoni, but they are by no means abundant and may already have reached the point of no return on their way to extinction.

Reptiles and amphibians that occur, or have occurred in Hong Kong are also of great interest to the naturalist, as is the abundant and little known insect life. Reptiles of note include the green turtle Chelonia mydas, which once came in large numbers to the beaches of many of the Hong Kong islands to breed. They are deified by the fisher folk and village farmers, as a symbol of longevity, but their eggs are not, being much prized for medicinal purposes especially by mothers, as they are reputed to be efficacious in the prevention of diarrhoea in young children. For this reason the village people keep watch sometimes for several days until the incoming turtles reach the shore; when they begin to lay, the eggs are collected for pickling. In 1962 and 1963 only one green turtle was known to have returned to Hong Kong, and during this period two others were killed in Hong Kong waters. In 1962 an attempt was made by the University and the Department of Agriculture and Fisheries to conserve the turtle eggs. The villagers on Lamma Island agreed that when turtles were sighted they would protect them and receive a bounty for every unmolested nest. A further inducement was made in the form of a per capita reward for each hatched turtle received by the University. But they did not keep to their word. They removed all the eggs, reburied six and demanded the price for finding the nest!

Several skinks, geckos, other lizards and numerous snakes aro still abundant in the Colony. The giant salamander Megalobatrachus davidianus may possibly also have inhabited our streams; these giant newt-like creatures can grow to a length of $5 \mathrm{ft}$. They are still numerous in China where they are found in mountainous regions notably those of western Kwangtung Province. At certain times of the 
year they are readily available in the Hong Kong food markets where they are sold alive for approximately 4 shillings a catty $\left(1 \frac{1}{\mathrm{l}} \mathrm{lb}\right.$.). Around the shores of Hong Kong coral, with its associated rich fauna, abounds. Illegal fishing with dynamite and also the recent illegal dynamiting of coral for use as a building material is destroying this under-water world. The extensive reclamation schemes are also obliterating a number of beaches where such animals as king crabs were frequently to be seen. King crabs, 20 inches long, like the small coral fishes, have very little food value. However to a hungry fisherman a little is better than none, so that without protection these too will disappear.

\section{The Need for a Survey}

What is urgently needed in Hong Kong is a full scale investigation into the state of the wildlife in the Colony. At present with the limited resources available this is not possible. There are however a number of naturalists and scientists like ourselves interested in this work, and it is hoped to attract visiting scientists to help us carry out such a survey. Already a rough estimate of mammals present has been gained from a number of sources, including hunters, trappers, naturalists, walkers and, on a limited scale, by capture-recapture methods. A full scale census of deer on Hong Kong Island is now being undertaken by a group of University staff, and we hope to be able to expand this work to other species and to other areas in the New Territories.

Over the past two years, with financial help from the Bishop Museum, Honolulu, one of us (P.M.M.) has carried out a preliminary survey of the numbers of mammal species which occur in the Colony and their relative abundance. Results so far seem to show that of the mammals only the muntjac deer, the masked palm civet and possibly the pangolin and ferret-badger would be sure to survive without belp in the proposed National Park. For the other mammals conservation may still be possible by careful preservation of animals present today and/or by the import of fresh stock from the Chinese mainland.

The ecological studies being carried out in Hong Kong to which reference has been made are supported, in part, by a Research Grant to the Department of Zoology from Sir Shiu Kin Tang.

\section{"THE BIC BAD WOLF"}

"Q UR attitudes towards predators border on biological nonsense. The morality fables of Aesop and the fantasy of Mother Goose, learned in early childhood, hopelessly precondition our views on predation. The wolf in 'Little Red Riding Hood' fares no better than the weasel in Burgess' 'Danny Meadow Mouse' . . . . A host of provocative words-all better expressions of man's feelings than of predators' performances-were and still are used to describe predators: wily, cunning, bloody in fang and claw, sly, beady-eyed, slavering, tavenous, stock-killing, cruel, treacherous. There are others. All have unpleasant implications; several suggest that some animals eat meat, perhaps even human flesh, that on some other occasions these animals skilfully take from us something that we want ourselves, and that their removal will ensure more of this something".Robert L. Rudd in "Pesticides and the Living Landscape". 